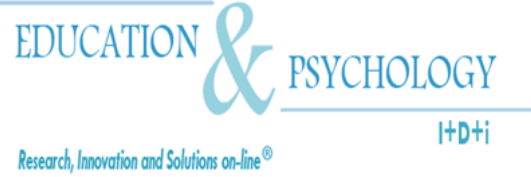

\section{Electronic Journal of Research}

in Educational Psychology

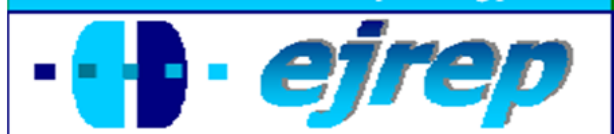

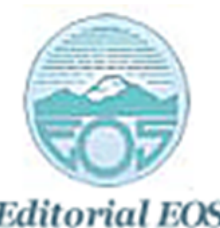

Editorial EOS

\title{
Utilizing Learning Promotion Potential (LPP) framework to facilitate the application of higher-order cognitive skills
}

\author{
Luke Okunya Odiemo
}

Department of Psychology, University of Nairobi

\section{Kenya}

Correspondence: Luke Okunya Odiemo. Department of Psychology, University of Nairobi, P.O. Box 3019700100. Nairobi, Kenya. E-mail: 1ukke7@gmail.com

(C) Education \& Psychology I+D+i and Editorial EOS (Spain) 


\begin{abstract}
Introduction. Different authors have proposed LPP as a pedagogical theorization framework to facilitate the linkage of psychological theory to teaching practice because it is useful for designing and assessing the effectiveness of pedagogical practice. This study aimed at testing the utility of the LPP-based theory-informed strategy at promoting learning and eliciting the application of higher-order cognitive skills with regard to plant nutrition.
\end{abstract}

Method. An 8-session LPP-based teaching sequence was designed and implemented on the basis of LPP principles. Using a comparative case study, the effectiveness of the writer's use of the designed sequence to teach plant nutrition to a mixed-gender class of 13/14 year-old Kenyan students was compared with that of an experienced and well-regarded Kenyan teacher teaching a comparable class in the same school, using the same amount of contact time.

Results. The findings show that LPP-based theory-informed strategy was more effective than the comparison teaching. Also the learners who experienced in the LPP-based teaching sequence progressively applied higher order cognitive skills in their heirarchy to the end of the teaching. Their comparison class counterparts' progress stopped at lower levels of the higher order cognitive skills hierarchy.

Conclusion: LPP provides a potentially useful framework by which it is possible to evaluate a theory-based teaching strategy to establish its effectiveness. However, it is still difficult to conclusively link the overt and covert processes.

Key words: Theory-informed practice, Evidence-based practice, Learning promotion potential framework, Pedagogical effectiveness.

Received: 05/04/09 Initial Acceptance: 05/18/09 Final Acceptance: 09/16/09 


\section{Utilidad de una estrategia de enseñanza basada en la Promoción del Potencial de Aprendizaje (PPA) como faciliadora de la aplicación de habilidades cognitivas superiores}

\section{Resumen}

Introducción. Diferentes autores han propuesto la Promoción del Potencial de Aprendizaje (PPA) como un esquema pedagógico teórico que facilita la conexión entre la teoría psicológica y la práctica educativa dado que su utilidad para diseñar y evaluar la efectividad de la práctica pedagógica. Este estudio tiene por objetivo evaluar la utilidad de la estrategia de la Promoción del Potencial de Aprendizaje basado en la elicitación de habilidades cognitivas de nivel superior.

Método. Un programa de 8 sesiones basado en la enseñanza en PPA fue diseñado e implementado siguiendo lo principios teóricos del PPA. Utilizando la comparación en dos supuestos: la efectividad de los autores en la utilización de una secuencia diseñada para PPA en la enseñanza de la nutrición a un grupo calse de estudiantes kenianos entre los 13-14 años, y otro grupo de profesores con otro grupo de estudiantes del mismo centro y con el mismo tiempo de clases

Resultados. Los resultados muestran que la estrategia PPA es más efectiva que la enseñanza convencional. Además, los estudiantes que recibieron el programa aplicaron de forma progresiva las habilidades cognitivas de nivel superior al final del programa. Sus compañeros del grupo control, sólo mostraron habilidades cognitivas de orden superior aunque en niveles menores.

Conclusión. PPA favorece la utilización de esquemas que hacen possible evaluar la estrategia de enseñanza y establecer su efectividad. Sin embargo, aún es difícil establecer la conexión entre los proceso de aprendizaje abiertos y encubiertos.

Palabras clave: práctica guiada, práctica, promoción potencial de aprendizaje, efectividad pedagógica.

Recibido: 04/05/09 Aceptación inicial: 18/05/09 Aceptación final: 16/09/09 


\section{Introduction}

Studies about teaching and learning have shown that school curricula usually aim at certain type learning objectives to be achieved by the learner, namely, affective, psychomotor and cognitive objectives. The affective includes aspects such as attitudes, motivation, interests and attitudes. The psychomotor handles issues of body kinetics and technical skills such as playing a guitar and typing. The cognitive involves aspects of memory and the development of intellectual skills and abilities (Bloom, 1956).

Pedagogical and Psychological research has been deployed in this area of study with an aim of understanding how teaching and thereby making it effective at achieving the above intended learning objectives (Leach \& Moon, 1999; Mortimore, 1999). In the recent decades there has been a marked shift from emphasis on learning outcomes to evaluation of the appropriateness of the process through which outcomes are achieved worldwide (cf. Leach \& Moon, 1999; Mortimore, 1999). But despite this shift in focus, pedagogical research has failed to significantly adopt research strategies that meet this demand. They still focus on designing strategies based on populist ideas of the moment such as constructivism and then evaluate their effectiveness in terms of overall learning outcomes, with little emphasis on the quality of implementation of such strategies to systematically accumulate evidence effective pedagogical practices (cf. Odiemo, 2005; Tomlinson, 2005). In response to the above challenge, the concept of LPP is proposed by Tomlinson (2008) as the core analytical, metatheoretical framework designed to facilitate the design and evaluation of theory-informed teaching strategies in a manner that generates evidence for impact of psychological learning theory on teaching practice.

The concept of LPP and its illustrative application in the review of the theories underpinning the development of higher-order cognitive skills

The central tenets of LPP are that teaching is a situated purposeful interaction of teachers, learners, goals of learning, classroom activities and resources (Tomlinson, 2008). In this process, teachers have no direct control over the learning process. Therefore, they only strive to facilitate learning through assisting learners to engage in particular learning activities within the teaching strategy and monitoring their participation to ensure successful engagement but not directly generating learning outcomes as that is a learner's responsibility 
(Odiemo, 2005; Tomlinson, 2008). This requires that the intended learning goals are clearly specified and a clear basis for assessment of the achievement of such capabilities in a learner clearly described in the teaching strategy.

For the purposes of ensuring efficiency in the choise of appropriate teaching/learning activities for the intended goal, Oser and Baeriswyl (2001) have argued that whereas research on effective teaching tends to describe overt classroom processes namely, the procedures characterising the respective teaching/learning activities; it is the psychological learning theory that actually explains the nature covert processes or learning functions i.e., the kind psychological states of the mind that the learners acquires as a result of the overt processes. Tomlinson (2008) argues that under this condition, overt processes by which the teacher achieves the intended learning goals can be describe as having an LPP on the grounds that: (a) they elicit the covert processes indicated by psychological learning theories as being necessary and relevant to the achievement of the intended learning goals; and (b) the teaching/learning activities designed on the basis of the tenets postulated by such theories enable the teacher to carry out his/her two major functions: assisting learning and monitoring its achievement within a particular teaching/learning context, "all other intervening factors, such as the state of the learner's mind, availability of resources, the teacher's competence among others, being equal".

The LPP concept further argues that psychological theories are varied yet relatively limited in their focus and scope. This is in line with Kelly's (1955) view that theories tend to have their "focus of convenience", i.e. they are intended to explain only certain aspects of reality, and even if they turn out to be relevant to a broader "range of convenience" as this is still likely to have its limits too.

An example is the Piagetian and post-Piagetian individual constructivist view of learning whose pedagogical implications among others point to learning by guided discovery as its focus of convenience, yet research on how far it can applied in terms of context has shown that the premises set by national school curricula in terms the aim of science teaching tends to limit its applicability. Critics of constructivism have argued that this approach to learning tends to focus on getting the learners to construct their own knowledge, but not what kind knowledge they actually construct, yet one of the main aims of the school curriculum is that they should acquire the scientific knowledge (cf. Mathews, 2000). Also the lack of material 
resources to facilitate the intended learning activities tends to limit its applicability in the developing countries (for details see Odiemo, 2005). Therefore, its range of convenience within the school setting in not limitless and that is worth taking into account when applying a given theory.

This means that pedagogical design should adopt an eclectic, but critical stance towards their adoption and use so that a number of theories can contribute towards generating a given teaching strategy instead adhering to populist ideas of the moment. That is, pedagogy should be open to any potential psychological learning theory's contribution, provided it is relevant, coherent and well evidenced as being capable of promoting the desired learning outcomes and able to enable a teacher assist and monitor learning (Odiemo, 2005; Tomlinson, 2008).

In the face of the challenge of the vast range of possible sources available for consideration when seeking the possible sources from which the intended overt process can be derived (cf. Shuell, 1996). Tomlinson (2008) holds that it is important to consider not only ideas specifically labeled as or claimed to be about "learning", but also anything that is in fact relevant to psychological learning processes because certain psychological learning process can achieve more than one covert learning process. For example, Odiemo (2005) explains that some theories such as information processing versions of cognitive psychology did not talk in terms of learning, but of memory, but processes such as "robust memory acquisition" or "storing information in the long-term memory" are normally characterized as aims of learning. Therefore the learning experiences that facilitate long-term memory consolidation may as well be regarded as possessing psychological learning processes needed for that kind of learning. This applied to theories regarding issues of practice/repetitive information processing which has largely been ignored in recent educational psychological constructivist ideas, for being associated with the discredited behaviorist paradigm (for details see Odiemo, 2005). Yet support for this psychological learning process comes, amongst the sources reviewed for the purpose of designing the intended teaching strategy, from information processing approaches to memory (cf. Baddeley 2000) and the cognitive psychology of skill (cf. Anderson, 1981; Tomlinson, 1981). It can be mentioned that it is also central to major paradigms not included in the above selection, such as neo-behaviorism with its large numbers of studies on verbal learning, and more recently also central to connectionist/neural net models such Parallel Distributed Processing (PDP) (cf. McCleland \& Rumelhart, 1986). 
Thus, any psychological learning theory that postulates such factors and can enable the teacher assist and monitor learning was up for selection in the design of teaching strategies aimed at facilitating the achievement of such an aim, no matter the psychological tradition of its origin. Furthermore, it is possible to note the complementarity and intercalation of various ideas characterizing most of selected of sources for review. It is worth noting the complementarity of some of the present ideas with some of the major psychological paradigms utilized, but not presented in the small illustrative selection undertaken for this study, such as that of the Vygotskian ideas and the later neo-Vygotskian socio-cultural work. An example is the cognitive psychology of skill and skill acquisition, specifically Tharp and Gallimore's (1988) appropriation of classic skill acquisition phases. This could be seen as a characterization of what pedagogically goes on in the Vygotskian Zone of Proximal Development (ZPD).

Another example of complementarity is the cross-source intercalation. Learning principles from meaningful learning theory such as meaningful acquisition of ideas (cf. Ausubel, 1963) are likely to be a subcomponent in the deployment of skill cycle ideas (Anderson, 1981) on learning. These can be applied in the explaining of strategies and feedback during skilful activity to facilitate a meaningful mastery. The complementarity of the need to avoid cognitive overload when presenting information, drawn from Sweller's (1988) cognitive load management theory, means that this too would play a role in the application of such ideas in the context of skill learning (cf. Kalyuga \& Sweller, 2004).

There is also need to be interested in psychological theory postulating processes that might not be directly leading to the attainment of the intended learning goal, but are necessary as one of the steps towards achieving that goal. For example, theories about the nature of aspects of cognition such as perception may be important as a part or particular layer of the learning process such as getting learners to identify evidence of the scientific theory during a demonstration.

The possibility of dynamic interrelations in different directions with regard to the various aspects of cognition is another factor for consideration. For example, perception is a necessary step in learning, but once learning has taken effect, it may also affect perception in that the mind will selectively perceive only certain things as a result of this training. Therefore insofar as perception is one of the stages in which information is processed for storage in the 
memory in the course of learning, then perception itself can be conceived as a being part of the learning process.

Taking the above consideration, an extensive review of psychological theories was undertaken to select the relevant theory for teaching plant nutrition. A considerable range of psychological learning theories were reviewed on the basis of the tenets LPP-framework (See Odiemo, 2005, for an illustrative review of these theories).

\section{The nature of higher-order thinking and their place in the school curriculum of Kenya}

Recent studies on skill acquisition have shown that in the day to day interaction with the world the three domains postulated by Bloom (1956) namely, affective, psychomotor and cognitive objectives are not as distinctive as such. Rather, they tend to interact with each other either explicitly or implicitly. For example, a psychomotor skill can manifest itself at a cognitive level in the form of declarative knowledge and at an effective and psychomotor level as procedural knowledge (Dreyfus \& Dreyfus, 1990; Eraut, 1994).

However, a review by Cakmakci (2005) showed that in most school science curricula the cognitive domain tends to be central in generating the goals of learning (Cakmakci, 2005). This view is corroborated by the situation in the Kenyan school curriculum about plant nutrition in that its learning aims emphasise the cognitive domain over the other two (cf. Kenyan Institute of Education Biology Syllabus, 2003).

\section{Purpose of the study}

Research undertaken by Odiemo (2005) evaluating the effectiveness of this framework in the area of plant nutrition in Kenya showed that it can largely fulfil its intended goals namely, facilitating the design; implementation and understanding the pedagogical effectiveness of both research-informed and non-research-based teaching strategies (see Odiemo, 2005 for details). The purpose of this research was to assay the utility the LPP-framework at, first, promoting the intended learning in terms of knowledge gains; and secondly, establishing the strategies' their effectiveness at facilitating the application of higher-order cognitive skills with regard to plant nutrition. The question was whether the LPP-based teaching strategy would be more effective at generating higher-order cognitive skill in a learner than its nonLPP teaching counterpart. 


\section{Method}

\section{Participants}

Two year-9 classes (i.e., first year of secondary school) of students aged 13-14 years were sampled. To qualify for secondary school, all year-8 pupils had to sit for a standardized national examination in Mathematics, English and Kiswahili languages, Science, Social studies and Business Education and meet certain requirements in terms of cut-off points. It was established that pupils had been allocated randomly to their classes on starting at their secondary schooling. The allocation of the author to the class where LPP-based teaching sequence was implemented and the comparison teacher's to the other class was done randomly. The author also checked the performances of the pupils in both classes in preceding continuous assessment tests and end of term examinations in biology and established the groups were quite comparable in that each group showed a mixture of ability ranging from high to low percentage scores. However, the author later established the LPP-class students had been rather unfortunate in that their regular biology teacher had been unwell for the whole of the preceeding school term and the school had found it difficult to get a regular replacement. Instead they had been relying on the voluntary services of some of the biology teachers who used to teach this class whenever they had a free period coinciding with the biology periods of this class on the timetable. The LPP-based class contained 31 students (17 boys, 14 girls; mean age 13.9 years, s.d. $=4.03$ years $)$ and the comparison class contained 33 students $(17$ boys, 16 girls; mean age 14.0 years, s.d. $=3.8$ years).

The author taught the LPP-based class. He had previously completed Kenyan teacher training at Bachelor of Education Degree level covering a period of four years including three months teaching practice. He also had one year of experience teaching in a Kenyan secondary school after graduating followed by some four years full-time postgraduate study abroad during which he doubled as a part-time teacher especially in the area of science in a number of schools mainly in Yorkshire, United Kingdom. The comparison class-teacher had 15 years teaching experience since gaining a Bachelor of Education qualification in Biology and Home Economics. It was clear that that teacher was held in high regard by the head teacher, other staff and pupils in the school, having taught there for 16 years and generating good results in the standardized national examinations. 


\section{Instruments}

\section{(a) The designed LPP-based theory-informed teaching strategy}

In designing the teaching sequence a literature search and extensive collegial consultation threw up a number of studies on children's ideas in plant nutrition that proved valuable in this process. However, there appeared to be very few investigations of teaching effectiveness, namely, Children's Learning in Science Project (1987) Barker and Carr (1989) and Leach and colleagues (2003). Notably, these studies evidenced a number of weaknesses in their application of psychological learning theory as already explained above.

On the basis of the LPP concept, a systematic review of current and historically available educational and psychological sources was undertaken. The author designed a set of eight teaching sessions on plant nutrition totaling 480 minutes in duration (for a summary of the teaching sequence see table 1 below), taught by him concurrently with the sessions of an experienced and respected biology teacher teaching the parallel class as normally, in a mixedgender secondary school serving a mixed-class urban community in the Rift Valley area of Kenya. As well as being involved in initial negotiations, the comparison teacher was interviewed concerning comparison teaching approach before, during and after the teaching process. The aim was to establish the rationale behind the comparison classroom activities.

The teaching/learning activities were designed in detail for multifunctional LPP in relation to the intended learning goals and sub-goals was such as to allow only illustrative indication (for details see Odiemo, 2005). As mentioned above, a number of psychological learning theories were reviewed. Based on these, the teaching was designed to include a considerable range of progressively sequenced teaching/learning activities, with overall emphases on shared generation of issues and sub-issues for pupil investigation using experimental and observational evidence. There was a deliberate avoidance, mainly through sub-topic sequencing and issue definition, of premature elicitation of well-evidenced misconceptions. The main focus of the design was to facilitate progressive consolidation and integration of cognitive gains by ensuring that the teaching-learning activities interactive and dialogic (cf. Leach \& Scott, 2002) 


\section{Procedure}

(a)Teaching and learning process: The teaching/learning process in both classes was implemented according to the designed sequence focusing on the intended learning goals.

(b) Recording of Teaching/Learning Processes. All sessions of both teaching conditions were video-recorded from a fixed position at the side of the classroom, by the author for the comparison class teaching and by a volunteer humanities teacher for the LPP-based teaching. In each class the teacher wore a digital Minidisc audio-recorder and two further such recorders were present on pupil group tables (LPP class) or individual pupils (comparison class) and recording during the whole duration. From these various recordings, the entire sequence of these recorded verbal interactions in each class was in due course carefully transcribed for both classes.

(c) Interview discussions with comparison teacher. There were informal dialogues concerning aims of the research and the need for the comparison teacher not to access the contents of LPP-based teaching before its completion. A brief pre-teaching interview was also held with the comparison class teacher to establish the broad nature of her teaching sequence and whether she was drawing on any formal theory for the design of her approach. There was post-teaching discussions, based in part on joint viewing of her video-recorded lessons where appropriate as a basis for stimulated recall, conducted, first, one week into the 3-week long teaching sequence and following its completion, to ascertain the comparison teacher's retrospective views on her own teaching implementation and to revisit the issue of whether she saw any particular formal theories as informing her teaching.

(d) Assessment of learning gains. A written test consisting of three questions, all involving open-ended responding, was administered to each class 'under examination conditions' by the first author as a pre-test a week before the teaching commenced, as immediate post-test one day after its last session and as a delayed post-test 3 weeks after the immediate post- test, unannounced on each occasion and taking up one class period of 40 minutes.

\section{Design of the study and Data Analysis}

In this study, the author undertook a comparative case study where whole teaching approaches were taken as two different intervention procedures. This was undertaken within a realistic learning environment where conditions are not easily replicable to allow the impact 
of every extraneous variable within the learning environment to be experimented to enhance the validity of the results as is the case with comparative case study design. Therefore the outcome of each approach was assumed to be the average impact of the all interacting factors within a given treatment condition (cf. Abadie, Diamond \& Hainmuller, 2007; Abu-Lughod, 2007).

The data recorded teaching/learning processes were analyzed first, to evaluate whether the quality of implementation adhered to the initial plan of the designed LPP-based sequence. Secondly, this data facilitated formative evaluation of the learners' progress in terms of knowledge. For this, multilayered/multi-aspect coding scheme was drawn up for each test question which allowed indication of various levels and aspects of understanding and misconception in each case. During coding, the researcher was blind folded to hide the pupils' identity as well as their class and test occasion. Lastly, the elicited thinking ability at the various stages of the teaching/learning process was also targeted. This was to characterize the effectiveness of LPP at eliciting higher-order thinking skills about some of the aspects of the concept in response to the teacher's probing of their knowledge and understanding as the lesson proceeded. For example, they were supposed to demonstrate analytical skill and discover that plants require water, light, and air at ago for growth and survival; they were also expected show higher reasoning skills by explaining the effect of light quality on photosynthesis etc.

Thus, the recorded data of pupils who wore minidisks was analyzed on the basis of Bloom's (1956) taxonomy's various levels of cognitive objectives for the emergent quality of understanding. A nomothetic approach was used to evaluate the appropriate demonstration of the targeted level of cognitive skill. (cf. Cakmakci 2005), That is, the learners' responses to questions requiring them to either demonstrate factual knowledge, comprehension, application, analysis, synthesis or evaluation about various aspects of the concept are judged against the standard scientific view In case the classroom discussion did not demonstrate any levels of the cognitive skill described above by Bloom (1956), it was categorized as "distorted view of plant nutrition".

The allocation of data to various categories underwent a member-checking process, a common procedure for ensuring research validity in qualitative research (Guba \& Lincolin, 1985 ) with an emeritus professor of pedagogy. There was member checking (cf. Guba \& Lincolin, 1985) using 15 scripts selected at random and one of the author's colleague's initial allocation of coding categories as basis, independent agreement rates of $89 \%, 87 \%$ and $80 \%$ 
were achieved by the author and two of his colleagues for the three questions, with differences being settled by discussion.

\section{Results}

Adherence to the design sequence and quality of Implementation of the teaching processes

\section{(a) LPP-based theory-informed teaching}

On the basis of the video and audio-recordings, supplemented by the author's recall and notes of field events, it was established that the designed LPP-based teaching sequence had been implemented largely according to plan laid out in the designed LPP-based teaching sequence above. That is, the sequence of activities and timings allocated to each activity was in the teaching plan was largely adhered to by the teacher. The learning activities were largely carried out, with the quality and degree of participation by students appearing to be generally acceptable as being the enactment of the informing psychological principles as judged jointly by the author and his colleague. However, in some sessions an unforeseen shortage of resources obliged reorganization of pupils from the intended eight groups of around four pupils per group into a smaller number of larger groups. In session 3, a shortfall in equipment forced groups as large as seven pupils in some cases and a need for teacher demonstration of the practical activity involved. In session 5, availability of only two as opposed to the requested eight sets of equipment meant that the author had to switch to a whole class demonstration of the effect of chlorophyll on light absorption and to radically re-organize the class so as to allow direct observation of leaf structure using half the number of microscopes that had been planned for. In session 8, involvement of pupils with an award ceremony involving the whole school curtailed the length of the session, forcing accelerated teacher-based, i.e., "chalk-and-talk", inputs by the author and preventing the planned linkage with and revision of major aspects of plant nutrition concept.

From the pupil side, it became clear that aspects of home disadvantagement were interfering with engagement in the allotted homework tasks by a noticeable enough number of pupils to necessitate explicit efforts to assist them to "catch up" so as to engage usefully in the activities of subsequent sessions. It is also worth mentioning that although the author had been careful to avoid any indication that he would teach differently from the pupils' usual teacher, audio recordings in an early session did pick up comments within one group indicat- 
ing initial unhappiness with his approach, along the lines of "why doesn't he teach us properly?" and "why doesn't he just tell us?". Such indications did not persist.

Also, the Kenyan curriculum about plant nutrition requires that learners should learn about factors limiting the rate of photosynthesis. However, literature on children's learning in this area tends to concentrate more on the chemical reaction characterizing the process of photosynthesis than on the limiting factors. Therefore the teacher of the LPP-based strategy designed it with prior awareness of the likely learning difficulties a child is likely to face while learning about limiting factors. This problem might have negatively influence the quality of implementation.

\section{(b) Comparison teaching}

From the interviews conducted with the comparison teacher, it was clear that her teaching was not informed by any explicit theoretical assumptions, apart from the teacher's emphasis that pupils' minds are empty and therefore knowledge needs to be provided to them by the teacher. In one interview prior to teaching, the following dialogue was recorded:

Researcher (R): do you know of any psychological theory of learning?

Teacher (T): Yes. I know the Pavlov one... the classical conditioning...the one that uses stimulusresponse strategy...not any other, I do not much about psychological ideas, just that one.

(R): since you are not familiar with psychology, do you have any ideas that you use when teaching?

(T): Yes. Personally, I like the idea that learners are tabular rasa

(R): How does this idea help you?

(T): it is good because then I can be able to tell whether a learner has absorbed well my content or not.

(R): And how does Pavlov's idea help you?

(T): Not really much. It is just good especially when I want them to rehearse or practice something, but I do not use for teaching as such.

In another interview held just after teaching the eighth session, the teacher would beconfirmed that, "teaching was normal", with no particularly unusual or negative features to mention.

Researcher: From your vast experience, would you say that your teaching styly has changed a lot ever since you joined the profession?

Teacher: aaah...Yes. It has developed a lot (laughter).

(R): What do you think has changed?

(T): Hmmm...I am now able to cover the content in time and spare time for revision for examinations unlike before when I could be caught by time (laughter)... I tend to see similar problem when university students come here for teaching practice.

(R): Is there anything you would like to improve in your teaching to make it better? 
(T): (laughter)...hmmm...currently I think I am satisfied with my style...my students are doing well in national examinations... may be unless they introduce new content in the syllabus, otherwise ....I think I am fine.

Analyses of the video recordings, audio recordings and their transcriptions (cf. Odiemo's $2005 \mathrm{PhD}$ thesis, chapter 7) indicates that the comparison teaching was considerably more limited in terms of the variety of teaching strategies than the LPP approach. It was generally characterisable as traditional "chalk-and-talk" with minimal teacher-pupil and pupilpupil interaction. Basically, it consistently tended to involve the teacher imparting information, predominantly by way of dictating notes to the class. Some use of whole class discussion was evident, but this tended to be in the "recitation-style" service of promoting grasp and detailed recording of teacher-dictated inputs - whether by way of preparation (e.g. "Who can tell me anything about nutrition?" - followed by dictated explanations and formal definitions of its different modes) or follow-up (e.g. "Who can tell me about the different modes of nutrition we saw yesterday?" - with further probing and corrective feedback where needed).

Whilst such strategies do appear to have some learning promotional likelihood regarding meaningful processing (see Odiemo's $2005 \mathrm{PhD}$ thesis, Chapter 8) this was being restricted in focus to teacher-designed fragments. It also appeared to be restricted in extent, not only by the dictation emphasis on precise surface recording of particular terms with correct spelling, but also by such processing producing a cognitive load that would be expected to drive out deeper processing in all but the most capable and confident of pupils. Far less practical work was evident than in the LPP-based teaching and what there was tended, likewise, to be in the service of concretely demonstrating teacher-imparted information, rather than for hypothesis-testing to facilitate discovery. Incidentally, regarding the aim of the practical activities, the teaching sequence seemed to be dictated according to how such activities are organized in the Kenyan national curriculum. Therefore it is a little bit difficult to conclude whether it is the teacher's own particular style of teaching or it is a style of teaching imposed onto the teacher by the syllabus.

\section{Summative results on the learners' understanding of the concept}

(a) Full Understanding Cumulative Score for Question 1 (Q1)

The question utilized to elicit a full understanding of plant nutrition was "how do plants get the energy they need to survive and grow?" Bearing in mind that the Kenyan school curriculum is organized in a spiral form (for details on spiral curriculum format see 
Bruner, 1966), the participants in this study had been introduced to plant nutrition at the primary school level. A coding scheme was drawn up designed to pick up the extent of a potentially multilayered and multi aspect nature of a grasp of plant nutrition/photosynthesis shown by learners in response to the test items. For example, a learner might understand at a general level that "plants make their own food" or that "plants get their energy through photosynthesis", or slightly more specifically, but only partially, that "plants make their energy from water and carbon dioxide", or more fully again, with each aspect of the answer that indicates that understanding being writen in italics and given a number in paréntesis. Thus the full understanding consisto f 21 aspects as indicated by as follows: "plants get their energy through the process of photosynthesis (1) when they make their own food (2) by chemically combining (3) carbon dioxide (4)which is taken in from the air (5) through the stomata (6) in the leaves (7), with water (8) which is taken in from the soil (9) through the roots $(\mathbf{1 0})$, using the chemical energy (11) generated from light energy (12) absorbed (13) by chlorophyll (14) in the leaves (15) to produce (16) glucose (17)/sugar (18)/food (19) that the plants use to directly provide their energy for survival (20) and generate biomasa for growth (21). This full understanding consists of about 21 aspects. Drawing from research on children's learning, it is desirable that a learner should know that plants actually generate glucose. Despite that, a less specific awareness that plants produce sugar or just simple food is equally accepted. However, full scientific understanding of these aspects required that one should be aware that plants produce glucose, which is a type of sugar that is actually food for the plants. That is why elements 17 , 18 and 19 are scored separetly whereby scoring all of the mis what constitutes a full scientific understanding of that aspect. Results by class and test occasion are presented for this quantitative measure in table 1.

Table 1. Full Understanding Cumulative means and s.d.s by class and test occasion.

\begin{tabular}{cccc}
\hline Score/ocasión & Class & Mean & Std. Deviation \\
& & & \\
\hline Q1 FU Score - Pre & Comparison Class & 4.45 & 2.706 \\
& LPP-based Class & 3.07 & 2.401 \\
Q1 FU Score - Post & Comparison Class & 4.42 & 3.117 \\
& LPP-based Class & 6.07 & 3.761 \\
Q1 FU Score - Del Post & & \\
& Comparison Class & 4.42 & 2.884 \\
& LPP-based Class & 7.00 & 4.057 \\
\hline
\end{tabular}

Since there are no procedures available for a two-way nonparametric analysis of variance procedure including repeated measures on one factor, on the argument that it makes 
sense to explore the extent to which respondents show the differing conceptual elements involved in a full understanding, that is, to treat them as quantitatively equivalent, and on the basis of the robustness of the procedures involved (cf. Tabachnick \& Fiddell, 1996) it was decided to subject these data to a general linear model two-way analysis of variance with repeated measures on the occasion variable.

As seen from from table 2 below it is seen that there was a statistically significant main effect of test occasion and a significant interaction effect of the two factors, i.e., class and test occasion, but no main effect of class. Post hoc contrasts indicated that whilst the LPPbased and Comparison class pre-test scores differed significantly by a straightforward $\mathrm{t}$ test $\mathrm{t}$ $=2.304, \mathrm{p}$ 0.025), when adjusted using the Bonferroni correction for decision-wise error rates, this difference in pre-test scores cannot be regarded as statistically significant. The same was true of the LPP vs Comparison class difference on the post-test FU scores $(\mathrm{t}=1.836, \mathrm{p}$ $\leq 0.071$ ). However, the difference between the two classes on the delayed post-test FU score was significant both by normal t test $(\mathrm{t}=3.164, \mathrm{p} \leq 0.002)$ and beyond the level required for $\mathrm{p}$ $\leq 0.05$ when Bonferroni-adjusted (which requires a level of $p \leq 0.0033$ ). For the LPP-based class, their pre-test mean scores differed significantly from their post-test and delayed posttest means scores under the Bonferroni adjustment, but their post-test mean did not differ significantly from their delayed post-test mean, even when not thereby adjusted. It should be noted that the significantly higher means recorded for the Comparison class when compared to the LPP-based class could be alluded to the fact that learning in the LPP-based class might have been distructed due to the absence of a regular teacher as explained above in the methodology section.

Table 2. ANOVA summary for Q1 Full Understanding cumulative scores by class and test occasion

\begin{tabular}{lccccc}
\hline \multicolumn{1}{c}{ Source } & Sum of Squares & d.f. & Mean Square & F & Sig. \\
\hline Within-subjects variables & 119.419 & 2 & 59.710 & 8.679 & .000 \\
OCCSN & 123.718 & 2 & 61.859 & 8.991 & .000 \\
OCCSN * CLASS & 770.546 & 112 & 6.880 & & \\
Error (OCCSN) & 1389.586 & 1 & 1389.586 & 249.431 & .000 \\
Between-subjects variables & 13.096 & 1 & 13.096 & 2.351 & .131 \\
Intercept & 311.977 & 56 & 5.571 & & \\
CLASS & & & & & \\
Error & & & & & \\
\hline
\end{tabular}


(b) Relevant Understanding Cumulative Score for Question 2(Q2)

The second open-ended question asked pupils to respond to the statement that "Plants are opposite to animals in that what animals breathe out, plants take in from the air" by indicating whether it is true or false and then providing the reasons for their answer. Although required to indicate whether true or false, the substantive score was awarded for the reasons for such an indication. An adequate response was taken to require indication of the following elements characterising the scientific view of plant nutrition (indicated as usual by in italics and associated number in bold font within the brackets): at night/in the darkness plants take in oxygen (1) and give out carbon dioxide (2) just like/similar/the same as animals (3) which all the time/always breathe in oxygen (4) and breathe out carbon dioxide (5); even though during the day/when there is light plants take in carbon dioxide (6) and give out oxygen (7). Therefore, comparably to Q1, a cumulative full understanding score was computed for Q2 by counting one point for each of the above 7 elements that were present in the answer and on the same bases as for Q1, these scores were analysed by class and test occasion using the general linear model for analysis of variance. Descriptive statistics are presented in table 3 below and the anova summary presented in table 4.

Table 3. Q2 Full Understanding descriptive statistics by class and test occasion

\begin{tabular}{clcc}
\hline \multicolumn{1}{c}{ Score/Ocasión } & \multicolumn{1}{c}{ Class } & Mean & Std. Deviation \\
\hline Q2 FU Score - Pre & Comparison Class & 3.00 & 1.275 \\
& LPP-based Class & 2.72 & 1.689 \\
Q2 FU score - Post & Comparison Class & 3.12 & 1.364 \\
& LPP-based Class & 2.94 & 1.703 \\
Q2 FU Score - Del Post & Comparison Class & 3.39 & 1.223 \\
& LPP-based Class & 2.94 & 1.458 \\
\hline
\end{tabular}

Table 4. ANOVA summary for Q2 Full Understanding cumulative scores by class and test occasion.

\begin{tabular}{lccccc}
\hline \multicolumn{1}{c}{ Source } & Sum of Squares & d.f. & Mean Square & F & Sig. \\
\hline Within-subjects variables & & & & & \\
OCCSN & 3.062 & 2 & 1.531 & 1.062 & .349 \\
OCCSN * CLASS & .621 & 2 & .310 & .215 & .807 \\
Error (OCCSN) & 181.626 & 126 & 1.441 & & \\
Between-subjects variables & & & & & \\
Intercept & 1775.880 & 1 & 1775.880 & 503.995 & .000 \\
CLASS & 4.598 & 1 & 4.598 & 1.305 & .258 \\
Error & 221.987 & 63 & 3.524 & & \\
\hline
\end{tabular}


From table 4 it will be seen that neither main effect approached significance and that the interaction effect, which is of more potential relevance, was even weaker. Further investigation showed that none of the pairs of means shown in table 4, in particular those for the LPP-and comparison class delayed post-tests, were significant even without applying the Bonferroni correction.

\section{(c) Relevant Understanding Cumulative Score for Question 3(Q3)}

The third open-ended question asked students to indicate whether they thought the statement "If plants are left in the dark, they will grow to a giant size" is true or false and to give the reasons for this response. The indication of true or false was not scored, but the reasons for the answer were scored. Once again, responses were coded on the basis of an adequate understanding of the relevant features including: "in fact plants will grow less than normal (1), because in order to grow (2) plants crucially need light (3) to drive the process of photosynthesis (4) so as to take in carbon dioxide (5) and thereby make food/ energy-giving substance/sugar (6). As in the comparable cases of Q1 and Q2, a cumulative full understanding score was computed for Q3 by counting one point for each of the above 6 elements that were present in the answer and on the same bases as previously, these scores were analysed by class and test occasion using the general linear model for analysis of variance. Descriptive statistics are presented in table 5 below and the anova summary is presented in table 6 .

Table 5. Q3 Relevant Understanding Cumulative Score descriptives by class and test occasion.

\begin{tabular}{llcc}
\hline \multicolumn{1}{c}{ Score/Ocasión } & \multicolumn{1}{c}{ Class } & Mean & Std. Deviation \\
\hline Q2 FU Score - Pre & Comparison Class & 2.78 & 1.845 \\
& LPP-based Class & 2.37 & 1.757 \\
Q2 FU score - Post & Comparison Class & 3.09 & 1.820 \\
& LPP-based Class & 2.81 & 1.981 \\
Q2 FU Score - Del Post & Comparison Class & 3.53 & 1.759 \\
& LPP-based Class & 2.85 & 1.895 \\
& & & \\
\hline
\end{tabular}

From table 6 below it will also be seen that as previously with question 2, neither main effect approached significance and that the interaction effect, which is of more potential relevance, was even weaker. Further investigation showed that none of the comparisons within pairs of means shown table 6, in particular those for the LPP-and comparison class delayed post-tests, were significant, even without applying the Bonferroni correction. 
Table 6. ANOVA for Q3 Relevant Understanding Cumulative Scores, class and test occasion

\begin{tabular}{lrrrrr}
\hline Source & Sum of Squares & d.f. & Mean Square & \multicolumn{1}{c}{ F } & Sig. \\
\hline Within-subjects variables & & & & & \\
OCCSNS & 11.299 & 2 & 5.649 & 2.330 & .102 \\
OCCSN * CLASS & 1.220 & 2 & .610 & .252 & .778 \\
Error (OCCSN) & 276.373 & 114 & 2.424 & & \\
Between-subjects variables & & & & & \\
Intercept & 1485.242 & 1 & 1485.242 & 278.886 & .000 \\
CLASS & 9.151 & 1 & 9.151 & 1.718 & .195 \\
Error & 303.561 & 57 & 5.326 & & \\
\hline
\end{tabular}

Effectiveness of teaching strategies at eliciting the application of higher-order cognitive skills

A degree of selectivity was applied in presenting illustrative patterns that could be explained by the characteristic differences inherent in the strategy and possibly explainable by the LPP framework. One of the ways of doing this was by linking the level of cognitive skill exhibited by the learner to the kind of learning activity used to teach it, as well as the kind of psychological processes intended. This kind of approach would enable the writer to argue step by step for the effectiveness of particular psychological theories drawn upon at promoting the respective cognitive skills regarding that particular aspect of the content. The aim in this paper was to establish whether there was any difference in the level of cognitive skill demonstrated by the some of the learners as a result of their learning experience. Therefore any emerging difference in the demonstrated higher-order cognitive skills was explained in terms of the difference in teaching approach (cf. Abadie, Diamond, \& Hainmuller, 2007; AbuLughod, 2007). Below are the results of the LPP-based class followed by those of the comparison class.

Was the LPP-based strategy effective at eliciting the application of higher level cognitive skills?

The results were presented by describing the level of cognitive skill demonstrated by the learners in various sessions of the LPP-based teaching sequence and compared it with that of control class over a similar session in the learning process. The results were presented according to the demonstrated cognitive skills, i.e., knowledge, comprehension, application, analysis, synthesis, evaluation for the various sessions. However, the development of cognitive skills being a progressive process, one is likely to effectively demonstrate a higher-order skill after achieving the preceding levels. For example, one is likely to be analytical about a 
phenomenon only after acquiring the relevant knowledge (Bloom, 1956). Therefore the writer was basically describing the highest cognitive skill demonstrated in a given session on the assumption that the learner already had ability to demonstrate the preceding skills. For example, in a session where analytical skill was demonstrated, then only that skill was described as it indicates that the learner(s) had attained the preceding levels (cf. Bloom, 1956). Below are the session by session results of the LPP-based class followed by those of the comparison class.

\section{Session 1. Distorted view of plant nutrition}

Session 1 begins with learners holding a distorted view of plant nutrition. The initial intention was to avoid using the term food, but because the term chlorophyll came up as being a source of energy for growth and survival for plants the teacher had to address the learner's understanding of it to enable the learner realize the difference between the two. The learner strongly held on the view that leaves are like a mouth for the plant. They use them to feed on light energy which is the food for plants as exhibited in the below discussion:

Teacher (T): But now let me ask you. Have you ever asked yourselves how plants manage to produce...to get all these things that we eat to get energy for survival and growth? Who can tell me how the plants manage to get these things? Who can try...lift up your hand. Yes

Jacquelyn: they get from the soil.

(T): what is your name by the way?

Jacky: Jacquelyn Jepkemboi.

(T): So Jackelyn believes that plants get their food from the soil. Who has a different thinking... who thinks of anything else? Let us list them down...

Benson: Through photosynthesis.

(T): through photosynthesis? What is photosynthesis?

Benson: Plants make their own food.

(T): yes, how do they make their own food?

Benson: Through chlorophyll

(T): what is chlorophyll?

Benson: In the leaf.

(T): How does a plant make food through chlorophyll?

Benson: Plants feed on sun using the leaf.

As part of the distorted view of plant nutrition, some of the learners held the misconception that respiration is the process by which plants feed. Generally, the learners exhibited the typical character of children of this age as described by researchers. Although they seemed analytical, it was difficult to characterize their ability vis-à-vis the concept of plant nutrition as this was not a systematic application of this higher-order cognitive skill on the basis of the 
intended propositional knowledge due to misconceptions of the basic terms such as "food" and "photosythesis."

\section{Session 2}

In session 2, the learners were mainly being scaffolded by the teacher to get them to implement their fair tests to check the validity of their prior ideas. Therefore it was difficult to judge the cognitive level at which the learners were operating bearing in mind that the teacher's role was fairly explicit in facilitating the learners to undertake that activity yet this analysis targets to characterize the learner's individual thinking ability. In Vygotsky's (1978) terms, the learner was operating in the Zone of Proximal Development whereby the more experienced partner was giving explicit instructions on how to go about the task.

\section{Session 3. Analysis level}

The learners had carried out a fair test to find out the kind of elements necessary for plant nutrition. They viewed the results in session 3. Some of the learners seemed to be experiencing a cognitive conflict (cf. Posner and colleague, 1982), partly doubting their prior conceptions, but also wanting to know whether their doubts are warranted. They had a distorted view of plant nutrition as demonstrated in session 1 , but this time they were required to analyze the systematically acquired evidence against their distorted view conception of plant nutrition.

From the data analysis of the classroom process of this session, no learner demonstrated a level higher than application of the already acquired knowledge. No one synthesized a new meaning that, plants make their own energy giving substances and to do that, they require all the elements-light energy, water and carbon dioxide from their observations as the expected of them by the teacher.

\section{Session 4. Analysis level}

The presence of sugar in plant-specimens had been tested in the preceding session. In this session, the teacher challenged the learners to explain where the sugar comes from as he scaffolded their explanations with his input drawn from the scientific knowledge. As a result, some of the learners demonstrated analytical skill by drawing from the evidence they had observed in an explanation that plants make their own sugar through the process of photosynthesis and, that photosynthesis requires light energy, carbon dioxide and water to happen. Some of the learners further demonstrated a high cognitive ability by way of analyzing the facts and concluding that photosynthesis is a process involving many elements and not just a single 
entity. There were attempts to synthesize the acquired by trying to explain how these elements facilitate the manufacture of food for the plants, but those who tried had trouble at scientifically describing the process since they had not yet been introduced to the right 'cultural' tools of the scientific community in the form of the terms and concepts used to explain this process by scientists (cf. Vygotsky, 1978). The excerpt below attempts to capture the above described scenario:

Teacher (T): Now ask yourself: What is photosynthesis? ... She said photosynthesis is the process by which plants make their own food or energy giving substances. But why are we referring to photosynthesis as a process?

Maina: Light (whispers).

(T): Yes Maina ....say it a bit louder please

Evelyn: It is a process whereby a plant takes in carbon dioxide and water and gives out oxygen and sugar.

(T): That is good...Yes Benson, would you like to try?

Benson: It is process where by a plant takes in carbon dioxide, water through the process of light and chlorophyll and produces sugar and oxygen.

(T): Both Evelyn and Benson has a very good idea about why photosynthesis is a process and not just light or chlorophyll or air. It is a process because it involves more than one thing to happen. Which things are involved in this process?

Maina: Air, carbon dioxide, water, chlorophyll, light, oxygen

(T): That is right...what happens in that process?

Evelyn: Carbon dioxide, light and water are used by the plant to give out oxygen and sugar.

The teacher got the class to experience the effect of light on chlorophyll solution by demonstrating to them that when a light spectrum is created using a glass prism and then place chlorophyll solution between the prism and the screen on the wall, only green light fluoresces. The intention of the teacher was get the learner to relate this evidence to their knowledge of light in physics and subsequently synthesis the meaning that "chlorophyll absorbs all the other wavelengths to drive photosynthesis except the green wavelength. Thus leaves normally appear green because the chlorophyll in them absorbs all the other wave lengths reflects the green one." Unfortunately, none of the learners managed to demonstrate the higher-order cognitive skill at the level of synthesis.

\section{Session 5. Analysis level}

The level of higher-order of cognitive skill demonstrated by some of the learners in session 5 was the analytical one. The teacher wanted the class to carry out a practical to demonstrate the importance of air to plant nutrition. Before that, he challenged the learners to make a prediction of what the results might be. Some learners managed to analyze facts and 
subsequently made their predictions

\section{Session 6. Evaluation level.}

In session 6 some of the learners demonstrated the analytical higher-order cognitive skill by analyzing facts in a practical aimed at showing them that gas can react with liquid to produce a solid substance by explaining why lime water turned milky after being covered with a green plant in an airtight bag for sometime in a dark room. By the end of this session, some of the pupils started asking explicitly evaluative questions seeking clarification.

Teacher: In the next lesson we are going to look at factors that limit the plants ability to produce sugar. Do you want to ask anything about we have learned today before we finish the lesson?

Oguk: What happens to the products of photosynthesis?

(T): What happens to the products of...

Oguk: Photosynthesis?

(T): That is a very good question. At the moment our time is almost up and I can not answer you fully now. That will be our last topic. After we have learned about the factors that affect...limit the rate of photosynthesis, our next topic will be, what happens to the sugar that a plant produces? That will be our last lesson in this topic. We shall discuss and see how... what exactly happens. Is there any question related to what we have learned today

In line with the above Posner and colleagues (1982) the class kept on searching for the fruitfulness of the newly encountered scientific view of plant nutrition by asking the teacher evaluative questions such as in the following excerpt:

Maina: Why does plants...under shade...grow slowly...but they are green?

Teacher (T): Why do plants under shade grow slowly yet they are green? Who can explain to us what happens to the plants under shade...they grow very slowly, but they are green? (Silence) Who can try? Yes...Benson.

Benson: When a plant is under the shade... when the rays of light reflect they don't get to the ground because it does not pass through the leaves of the bigger overshadowing tree.

(T): Yes, some rays normally pass through. Who can...who can...put it more clearly than...who can help him put it more clearly? He has got the idea...but it needs some clarity.

James: The plant gets less sunlight to react...to make the water and the air to react to make sugar.

(T): Yes...it gets light, but the rays are too weak and therefore too little to facilitate effective production of sugar for the plant to use. In the next lesson, we are going to look in details at why a plant which is under shade does not grow as healthy as the one under sunshine.

\section{Session 7. Analysis level}

In this session some learners were now analyzing the impact of aspects such as the impact quantity and quality of these elements on plant nutrition as shown in the conversion below:

Teacher (T): Any other question? (silence) If there is nothing...Yes. Last one.

Oguk: What will happen to the plant which gets less light? 
(T): What did you ask?

Oguk: What will happen to the plant which gets less light?

(T): What happens to the plant which gets less light such a plants that grow under a shade?

Prisca: The plant will not grow.

(T): The plant will not grow. Why?

Prisca: Because it does not absorb enough light

(T): why is a plant affected when it does not absorb enough light?

Prisca: Photosynthesis stops.

(T): the plant will not grow well because it will not absorb enough light to enable carbon dioxide and water to break down effectively to produce enough sugar for growth and survival. When less sugar is produced due to low rate of photosynthesis the plant does not well.

\section{Session 8 .}

This session was planned on the assumption that by this stage of the learning process the learner was supposed to have managed to process the scientific knowledge about plant nutrition at the higher-order cognitive skill of analysis. Indeed some learners had demonstrated these levels of higher-order cognitive skills. Therefore the aim here was, first, to get the learner to synthesize new knowledge from the facts they were going to encounter in order to acquire the knowledge that plant biomass is usually generated from a combination of sugar manufactured through photosynthesis and minerals from the soil. Secondly, the learner was expected to evaluate the kind of changes in conception of plant nutrition that had taken places in their prior understanding of this concept. The teacher demonstrated by burning a piece of wood generating smoke of which carbon dioxide is part of and water vapor into the atmosphere leaving behind the salts in the form of ashes. However, no learner demonstrated the ability to synthesize knowledge from this evidence to explain the smoke and water were actually made up the initial chemical taken in by plants to make sugar, i.e., $\mathrm{CO}_{2}$ and $\mathrm{H}_{2} \mathrm{O}$ while salts taken from the soil remained as ashes. The teacher had to explain to the class the meaning of that evidence. Secondly, no learner demonstrated the ability to evaluate the developments in their understanding of plant nutrition. Generally, the LPP strategy managed to elicit the application of higher-order cognitive skills during in some of the learners in the course of the learning.

Was the Comparison strategy effective at eliciting the application of higher level cognitive skills?

The analysis of the teaching learning process in the comparison class revealed a number of issues that could be important to understanding these finding. During the first two sessions, the teacher introduced terms imparting knowledge to the learners. The teacher described the structure of the plant leaf. 


\section{Session 1. Knowledge level}

The first session began by the teacher asking the learners what they understood by some of the terms related to plant nutrition and how the plants utilize the food they take in, a question the author considered to be a basis for reinforcing the learners' everyday conception of plant nutrition and probably making it difficult for them to change because plants do not take in food, but they manufacture it. Anyway, since the teacher used to ask the pupils to read about the topic beforehand, students seemed to have basic knowledge of various terms and concepts, but only at the higher-order cognitive skill level of "knowledge".

\section{Session 2. Application level}

In the second session, the teacher attempted to get the learners to explain why the leaf is darker on the upper side. But once the learner states that it is because it is the place where photosynthesis takes place, the teacher does not challenge the learner to explain further what photosynthesis means but simply carries on trying to get the learners to define other newer terms such the food as shown in the discussion below.

Teacher (T): ...let us look at a completely green leaf...let that colour not confuse us...look at another...at the green leaf...then look at the darkness of the colour...the green colour...on the top and on the bottom...tell me the difference... which side is darker than the bottom?

Pupil (b): The top.

(T): the top is darker? isn't it?

Pupils: Yes

(T): Why do you think the top is darker...yes?

Pupil (b): Photosynthesis.

Pupil(g): because that is where photosynthesis takes place mostly, isn't it?

(T):...that is where photosynthesis takes place mostly, isn't it? The is...the... the top...the upper side is where we have the palisade mesophyll which has more chloroplasts, which contain a lot of green colour, isn't it? That is why the top is darker than the bottom...

For the remaining part of the session, the teacher carried out the lesson by mainly dictating the notes to the learner and occasionally getting the learner to state one or two facts about plant nutrition. Despite such a teacher-centered session, the learners also showed the capability to apply the knowledge about the concept as in the following instance. The second session proceeded with the teacher teaching about the leaf structure. Although the teacher mainly dictated notes, at one point in this session, the teacher got the learners to apply their knowledge of plant nutrition by relating the color of the leaf with its importance to photosynthesis when the learners managed to explain why the top of the leaf is darker than the lower 
part.

\section{Session 3. Knowledge level}

The third session focused on trying to show the link between the various aspects of the process of photosynthesis with the role played by the various organs of the leaf even. Some of the learners demonstrated the knowledge without necessarily being able to demonstrating the comprehension of what those elements are used for in plant nutrition as shown below:

Teacher (T): we require water... why is water required? Why is water required?...for what purposes...to perform what functions? Water is required for what?...yes...

(T): Where does a plant get water from...

Pupil: rain (a pupil mumbles)

(T): ...yes?

Pupil(b): From the soil

(T): From?

Pupil: The soil.

(T): From the soil...ok...so, the water is absorbed by the roots from the soil...the water the plant uses is absorbed from the soil...the water the plant uses is absorbed from the soil...the water the plant uses is absorbed by the roots from the soil.

\section{Sessions 4-8. Distorted view of plant nutrition}

In most of the remaining sessions, some of the learners in this class demonstrated a distorted view of plant nutrition as in the following discussion recorded in session 8 during an experiment to test leaves for starch, an activity aimed at demonstrating the plausibility that photosynthesis had taken place. The learner who had responded to the teacher's questions demonstrated a misconception that the product of photosynthesis is starch.

Generally, the learners rarely moved beyond the point of application in terms of cognitive skill. However, as explained above, it is difficult to explain whether student actually did not have the ability at other levels, because the teacher styled the learning process in such a way that her role was to "fill in the gaps" of the learner's knowledge about the concept. For example, in session 3 the teacher gave the learners the homework of reading about the "simple" aspects of plant nutrition such as the definition of photosynthesis, while she focused on more "advanced" aspects such as the types of sugar produced by plants.

General reflections on how successful the LPP-based strategy was at eliciting the utilization of higher-order-cognitive skill

The manner in which last four sessions unfolded made it difficult to clearly characterize the learners' level of higher-order cognitive skill demonstrated. The learners seemed to 
develop negatively in that after having started off by demonstrating higher-order cognitive skills in the first three sessions, they seemed to degenerate into a distorted understanding of the concept, yet according to Bloom (1956) they ought to have been advancing to higherorder cognitive skills. Despite that, generally the analysis of the learning process data from the comparison class showed that some learners were able to demonstrate three levels of cognitive skill regarding plant nutrition namely, knowledge comprehension and application.

Comparative effectiveness of LPP-based versus comparison strategy at eliciting the utilization of higher-order-cognitive skill

It possible to argue the results seemed to support the hypothesis that the LPP-based strategy had the latent potential to promote the acquisition of higher cognitive skills about plant nutrition than its non-LPP counterpart. Secondly, there is evidence to support the hypothesis that based on its principle of the need to monitor the learning the LPP framework facilitated the evaluation of both teaching strategies at the sub-component level. This enabled the establishment of linkage between the teaching/learning activities and their ability to elicit particular higher-order cognitive skills over the concept of plant nutrition. Generally, there is evidence that that LPP-based strategy is not only effective at facilitating the understanding of the concept, but also getting the learner to practice the application high-order cognitive skill using the acquired knowledge.

\section{Discussion and conclusion}

Due to increasing interest in theory-informed teaching there is a need to understand the influence that psychological learning theory has on teacher effectiveness. Comparative studies have been conducted to establish the impact of theory-informed teaching strategies on the learners' understanding of various concepts (cf. Barker \& Carr, 1985; Barker \& Carr 1989; CLISP, 1987; Leach and colleagues, 2003) to establish the evidence of the impact of theory on pedagogical effectiveness. However, Odiemo (2005) has criticized these efforts for their arbitrariness and narrowness in the sources the select to inform their design and implementation of their teaching strategies among other shortcomings (cf. Odiemo, 2005).

This study is therefore in line with the evidence-based tradition of research in education, which aims to establish the influence of theory onto teaching (cf. Leach and colleagues, 2003; Leach \& Scott, 2002). This study was focused on the impact of an LPP-based teaching strategy on the development of cognitive abilities about plant nutrition in a group of learners. 
The main assumption behind this evaluation was that LPP-based teaching strategy would be superior "other things equal". This qualification applies mainly to implementation quality: that is, it is only claimed that this basis for design should produce superior effects when such a design is adequately implemented in practice, consistent with the LPP conceptual framework.

As per the interviews with the comparison class teacher, the comparison teaching was not based on any explicit theoretical principle, except that the comparison teacher had a belief that learners are tabula rasa and ought to be told things, which might count as the teacher's "personal theories" about learning. Although this is the idea that drives the teacher's approach to pedagogy, it does not qualify as a psychological learning theory as such because there is hardly any evidence to support the claim that learners are actually tabula rasa neither does it specify any principle that provide guidance on how tabula rasa beings should be taught. Therefore the writer considers any pedagogy that draws upon such an as being without any underlying psychological theory to inform it. As shown by the results, such pedagogy seems to be detrimental the learners' ability to deploy higher-order thinking about plant nutrition. The results showed that half way the teaching sequence in the comparison class, the learners' ability to deploy higher-order cognitive skills degenerated instead of advancing to more advanced skills. From LPP framework based evaluation of the comparison teaching sequence, this situation could e attributed to the fact the teacher simply lacked creative activity to facilitate meaningful learning and therefore relied on dictation of the notes to the learners.

As a group, the LPP-based class demonstrated a progressive ability to deploy higher level of cognitive skills almost throughout the teaching sequence than their comparison counterparts. Thus, the results were consistent with the predictions. Alternatively, it should have been hypothesized that the comparison class would outperform the LPP-based class because the teacher was much more experienced and well acquainted to the learners than the LPPbased class teacher. However, the results demonstrate the opposite.

Qualitatively, the results demonstrate that application of theory to teaching can greatly influence the achievement of the intended learning outcome even just on the basis of one teaching strategy. Although the learners in both classes were not necessarily making discoveries of new knowledge, the LPP-based class learners were engaging with the content of learning at a more advanced cognitive level cognitive. A deeper understanding of the role that 
psychological learning theory van play in enhancing learning can be useful to informing practice in the upcoming fields of study such self-regulated learning where research is on-going to establish how psycho-educational advising can be used as a strategy to improve practice (for details about psychoeducational advising see Fuente \& Medialdea, 2007; Sanchez, Fuente \& Peralta, 2007).

However, being comparative case study, a number of extraneous factors might have influenced the results. This included lack of equipment for the LPP-based teacher which hampered the implementation quality, the learners' unfamiliarity with style of teaching that requires them to actively participate in the learning process instead of the usual passive mode dominated by dictation of notes and the unintended selective application the tenets postulated by various theories during the implementation.

On the other hand, despite not being familiar with a vast array of psychological theories as required by the LPP framework, the comparison teacher still managed to promote the development of higher level cognitive skills such as application of knowledge using her mode of dictation. Therefore as explained earlier, it would be helpful to understand the intention for strongly reminding learners to read about photosynthesis beforehand as this might have had some influence on the results. Also it would be useful to address the factors that negatively influenced the implementation of LPP-based strategy to effectively explain its effectiveness.

The results of this study would be useful at understanding the impact of some of the factors claimed to be hindering the development of cognitive skills in children and how appropriate pedagogies can be derived from the perspective of the available theory (cf. Schimidt, Marohn \& Harrison, 2005). Understanding how to empirically evaluate the utility of the LPP framework would be useful at promoting theory-based practice and evaluating its impact on the development of children's knowledge and cognitive skills so as to discover the kind of learning experiences that are useful (cf. Leach \& Scott, 2002). The methodology applied here would contribute to the overall development of knowledge about how to the effectiveness of teaching strategies and resulting learning outcomes in a broader sense as recommended (cf. Leach \& Scott, 2002).

It would be a great over statement to claim these result can be generalized outside the contexts of their study since the sample was relatively small. More research is also required 
at a more refined level to get at the link between the kind of teaching/learning activities that are effective at promoting the desired cognitive skills and the kind of learning processes the elicit in the learner (cf. Oser \& Beariswyl, 2001; Tomlinson, 2008).

\section{References}

Abadie, A., Diamond, A. \& Hainmuller, J. (2007). Synthetic control methods for comparative case studies: Estimating the effect of California's tobacco control program. Retrieved 06/21/08 from http://courses.gov.harvard.edu/gov3009/spring07/hainmueller.pdf

Abu-Lughod, J. (2007). The challenge of comparative case studies. City analysis of urban trends, culture, theory, policy, action, 11(3), 399-404.

Anderson, J.A. (Ed.). (1981). Cognitive skills and their acquisition. Hillsdale: Lawrence Erlbaum Associates.

Ausubel, D.P. (1963). The psychology of meaningful verbal learning: an introduction to school learning. New York, London: Grune and Stratton Inc.

Baddeley, A.D. (2000). Short-term and working memory. In E. Tulving \& F.I.M. Craik (Eds.), The Oxford Handbook of Memory (pp 77-92). New York: Oxford University Press

Barker, M. \& Carr, M. (1985). Photosynthesis: learning outcomes. Working Paper No.228, Science Education Research Unit, University of Waikato, Hamilton, New Zealand.

Barker, M. \& Carr, M. (1989). Teaching and learning about photosynthesis. International Journal of Science Education, 11(1), 49-56.

Bloom, B.S. (Ed.). (1956). Taxonomy of educational objectives: The classification of educational goals- Handbook I: cognitive domain. New York: McKay.

Cakmakci, G. (2005). A cross-sectional study of the understanding of chemical kinetics among Turkish secondary and undergraduate students. Unpublished Ph.D. thesis, The University of Leeds, Leeds, United Kingdom.

Children's learning in science project (CLISP) (1987). CLISP in the classroom: Approaches to teaching energy, particulate theory of matter, plant nutrition. Centre for Studies in Science and Mathematics Education (CSSME), University of Leeds, United Kindgom.

Dreyfus, H. L. \& Dreyfus, S. E. (1990). What is moral maturity? A phenomenological account of the development of ethical expertise. In D. Rasmussen (Ed.), Universalism versus communitarianism. Boston: MIT Press. 
Eraut, M. (1994). Developing professional knowledge and competence. London: Falmer PreSS.

Fuente, de la J. \& Medialdea, A.M.L (2007). RDI Advising model for improving the teaching-learning process. Electronic journal of research in educational psychology, 13, 5(3), 879-908.

Guba, E.G. \& Lincolin, Y.S. (1985). Naturalistic inquiry. Beverly Hills, CA: Sage

Kalyuga, S. \& Sweller, J. (2004). Measuring knowledge to optimize cognitive load factors during instruction. Journal of educational psychology, 93(3), 558-568.

Kelly, G.A. (1955). Psychology of personal constructs. New York: Norton

Kenya Institute of Education (2003). Secondary School Biology Syllabus. Nairobi: Kenya Institute of Education.

Leach, J., Amettler, J., Hind, A., Lewis, J. \& Scott, P. (March, 2003). Evidence-informed approaches to teaching science at junior high school level: outcomes in terms of student learning. Paper presented at the Annual Meeting of the National Association for Research in Science Teaching, Philadelphia, U.S.A, as part of the symposium 'Evidence-based practice in science education'.

Leach, J. \& Moon, B. (Eds). (1999). Learners and pedagogy. London: Paul Chapman publishing/Open University.

Leach, J. \& Scott, P. (2002). Designing and evaluation science teaching sequences: an approach drawing on the concept of learning demand and a social constructivist perspective on learning. Studies in Science Education, 38(1), 115-142

Mathews, M.R. (2000). Editorial. Science and education, 9(6) 491-505.

McClelland, J.L. \& Rumelhart, D. (1986). A distributed model of human learning and memory. In D. Rumelhart \& J.L. McClelland (Eds.), Parallel distributed processing: Explorations in the microstructure of cognition Volume.2 (pp.170-215). Cambridge, Massachusetts \& London: The MIT Press.

Mortimore, P. (Ed.). (1999). Understanding pedagogy and its impact on learning. London: Paul Chapman.

Odiemo, L. O. (2005). The utility of the learning promotion potential framework for the teaching of plant nutrition in a Kenyan secondary school context. Unpublished $\mathrm{PhD}$ Thesis, School of Education, University of Leeds, Leeds, United Kingdom.

Oser, F.K. \& Baeriswyl, F.J. (2001). Choreographies of teaching: bridging instruction to learning. In V.Richardson (Ed.), Handbook of research on teaching ( $\left.4^{\text {th }} \mathrm{ed}\right)$ (pp.1031-1065). Washington: American Educational Research Association. 
Posner, G.J., Strike, K.A., Hewson, P.W. \& Gertzog, W.A. (1982). Accommodation of a scientific conception: toward a theory of a conceptual change. Science education, 66(2), 211-227.

Sanchez, D.M., Fuente, de la J., \& Peralta, J.F. (2007).Improving the teaching-learning process through psychoeducational advising. Electronic journal of research in educational psychology, 13, 5(3), 853-878.

Scmidt, H.J., Marohn, A. \& Harrison, A.G. (2006). Factors that prevent learning in electrochemistry. Journal of research in science teaching, 1, 1-26

Scott, P., Hind A., Amettler J., Leach J. \& Lewis J. (August, 2001). Designing and implementing science teaching drawing upon research about science teaching and learning. Paper presented at the conference of European Science Education Research Association, Thessaloniki, Greece, as part of the symposium 'Using research to improve practice in science education'.

Shuell, T. (1996). Teaching and learning in the classroom context. In D.C. Berliner and R.C. Calfee (Eds.), Handbook of educational psychology (pp. 726-764). New York: Macmillan.

Sweller, J. (1988). Cognitive load during problem solving: effects on learning. Cognitive science, $12(2), 257-285$.

Tharp, R.G. \& Gallimore, R. (1988). Rousing minds to life: Teaching, learning and schooling in social context. Cambridge: Cambridge University press.

The Design-Based Collective (2003). Design-based research: an emerging paradigm in educational inquiry. Educational researcher, 32(1), 5-8.

Tomlinson, P. (1981). Understanding Teaching: Interactive educational psychology. Maidenhead: McGraw-Hill.

Tomlinson, P.D. (2003). Towards a non-deterministic conception of pedagogical effectiveness: The concept of learning promotion potential and some of its implications. Seminar paper, School of Education, University of Leeds, Leeds, United Kingdom.

Tomlinson, P.D. (2005). Introduction. British Journal of Educational Psychology, Monograph Series, 2(3), 1-10.

Tomlinson, P.D. (2008). Psychological theory and pedagogical effectiveness: The Learning Promotion Potential framework. British journal of educational psychology, 78(4), 505-526.

Vygotsky, L. S. (1978). Mind in society: the development of higher cognitive processes. Cambridge, MA: Havard University Press. 
Luke Okunya Odiemo

[This page intentionally left blank] 